OPEN ACCESS

Edited by: Andrei Surguchov, University of Kansas, United States

Reviewed by: Antonio J. Herrera, Universidad de Sevilla, Spain Rocío Martínez De Pablos, Universidad de Sevilla, Spain

*Correspondence:

Hong Jiang hongjiang@qdu.edu.cn

Received: 20 November 2017 Accepted: 15 January 2018 Published: 26 January 2018

Citation: Bi M, Jiao $Q, D u X$ and Jiang $H$ (2018) Glut9-mediated Urate Uptake Is Responsible for Its Protective Effects on Dopaminergic Neurons in Parkinson's Disease Models. Front. Mol. Neurosci. 11:21. doi: 10.3389/fnmol.2018.00021

\section{Glut9-mediated Urate Uptake Is Responsible for Its Protective Effects on Dopaminergic Neurons in Parkinson's Disease Models}

\author{
Mingxia Bi, Qian Jiao, Xixun Du and Hong Jiang*
}

Department of Physiology, Shandong Provincial Key Laboratory of Pathogenesis and Prevention of Neurological Disorders and State Key Disciplines: Physiology, Medical College, Qingdao University, Qingdao, China

Considerable evidence has shown that elevated plasma or cerebrospinal fluid (CSF) urate levels correlated with a reduced risk of Parkinson's disease (PD). Based on its anti-oxidative properties, urate might serve as one of promising neuroprotective candidates for PD. However, how urate is transported through cell membranes to exert its effects inside the cells in PD is largely unknown. To elucidate this, we showed that increased intracellular urate exerted its neuroprotective effects against 1-methyl4-phenylpyridinium (MPP+)-induced neurotoxicity in MES23.5 cells and elevated urate could antagonize 1-methyl-4-phenyl-1,2,3,6-tetrahydropyridine (MPTP)-induced nigral dopaminergic neuronal death in urate oxidase (UOx) knockout $(\mathrm{KO})$ mice. Its transporter, glucose transporter type 9 (Glut9), was observed up-regulated, which was caused by the activation of p53. These protective effects could be abolished by Glut9 blocker and p53 inhibitor. These results suggested that Glut9 was a functional urate transporter, whose up-regulation by activation of p53 resulted in the increased intracellular urate levels in PD models. Our findings suggest that Glut9 could be modified to modulate urate levels in dopaminergic neurons and urate-elevating strategies without increasing systemic levels to avoid side effects might serve as a potential therapeutic target for PD.

Keywords: Parkinson's disease, urate, urate oxidase, Glut9, p53, MPTP

\section{INTRODUCTION}

Parkinson's disease (PD) is a common neurodegenerative disorder characterized by a progressive loss of dopaminergic neurons in the substantia nigra (SN) and subsequent dopamine depletion in the striatum (Hornykiewicz, 1998; Song et al., 2017). The exact etiology and pathogenesis responsible for dopaminergic neuronal degeneration are largely unknown. Accumulating

\footnotetext{
Abbreviations: ABCG2, ATP-binding cassette subfamily G member 2; Akt, protein kinase B; ARE, antioxidant response elements; CSF, cerebrospinal fluid; Glut9, glucose transporter type 9; GSK3 $\beta$, glycogen synthase kinase 3 $\beta$; MAO-B, monoamine oxidase-B; $\mathrm{MPDP}^{+}, 1$-methyl-4-phenyl-2,3-dihydropyridinium; $\mathrm{MPP}^{+}$, 1-methyl4-phenylpyridinium; MPTP, 1-methyl-4-phenyl-1,2,3,6-tetrahydropyridine; MRP4, multi-drug resistance-associated protein 4; MTT, 3-(4,5-dimethyl-2-thiazolyl)-2,5-diphenyl-2-H-tetrazolium bromide; Nrf2, nuclear factor E2 related factor 2; OAT, organic anion transporter; PD, Parkinson's disease; ROS, reactive oxygen species; SLC2A9, solute carrier family 2 member 9; SN, substantia nigra; SOD1, superoxide dismutase 1; TH, tyrosine hydroxylase; UOx, urate oxidase; URAT1, urate anion transporter 1; 6-OHDA, 6-hydroxydopamine; $\Delta \Psi \mathrm{m}$, mitochondrial transmembrane potential.
} 
evidence indicates that oxidative stress is a major contributor in the pathogenesis of PD (Jenner and Olanow, 1998; Schapira et al., 1998), suggesting that antioxidants could have some potential usages in PD treatment.

Urate, an end product of purine metabolism in humans, is a natural and powerful antioxidant (Ames et al., 1981; Becker, 1993). Although high plasma urate levels are risk factors for several metabolic syndromes, such as gout and type 2 diabetes mellitus, they could decrease the incidence of PD and its progression (Hayden and Tyagi, 2004; Schwarzschild et al., 2008; Ascherio et al., 2009). Davis et al. (1996) first described men with serum urate levels above the median had a decreased rate of idiopathic PD. Subsequent epidemiological and experimental studies all suggest that higher dietary urate intake or early diagnosis of gout has a lower risk of PD (Alonso et al., 2007; Gao et al., 2008). In addition, reduced urate levels in the $\mathrm{SN}$ have been observed prior to clinical symptoms in PD patients (Church and Ward, 1994), which is more likely a predictor of PD diagnosis in the prodromal phase and neuroprotective intervention before the onset of neurological symptoms (Fang et al., 2013; Ascherio and Schwarzschild, 2016).

The neuroprotective effects of urate in PD have been studied by several groups. For example, urate could alleviate the impaired motor performance in $\mathrm{PD}$ animal models in vivo and prevent the degeneration of dopaminergic neurons in vitro (Gong et al., 2012; Zhu et al., 2012). Notably, these effects of urate are shown to depend on its intracellular levels (Cipriani et al., 2012a; Zhang et al., 2014). However, urate is an organic anion and could hardly pass through cell membranes in the absence of its transporters, a question remains to be answered: how is extracellular urate transported into cells to exert its effects? Up to now, the related urate transporters include glucose transporter type 9 (Glut9), urate anion transporter 1 (URAT1), organic anion transporter (OAT), ATP-binding cassette subfamily G member 2 (ABCG2) and multi-drug resistance-associated protein 4 (MRP4; Reginato et al., 2012). Among these, Glut9, encoded by solute carrier family 2 member 9 (SLC2A9), is a candidate that could determine the serum urate concentration (Dehghan et al., 2008; Wei et al., 2011). Meanwhile, Glut9 is associated with faster clinical progression and earlier age at onset of PD, whose single nucleotide polymorphisms related to lower urate levels could modify susceptibility to PD (Facheris et al., 2011; González-Aramburu et al., 2013; Simon et al., 2014).

In the present study, we aimed to explore the urate transport mechanism involved in its neuroprotective effects on dopaminergic neurons using MES23.5 dopaminergic cells and urate oxidase (UOx) knockout (KO) mice. Mutation in UOx, a liver-specific uricase that oxidizes urate to allantoin in most mammals, could cause higher levels of urate in blood and cerebrospinal fluid (CSF) in humans (Wu et al., 1992; Paganoni and Schwarzschild, 2017). These findings might provide a novel potential mechanism and direct evidence for investigating antioxidant, such as urate, as a therapeutic target for PD.

\section{MATERIALS AND METHODS}

\section{Cell Culture and Treatment}

The rodent MES23.5 cell line was a kind gift from Dr. Wei-dong Le at Dalian Medical University (Dalian, China). MES23.5 cells were cultured in Dulbecco's modified Eagle's medium (DMEM)F12 (Gibco, USA) containing Sato's components growth medium supplemented with $5 \%$ fetal bovine serum, 100 units $/ \mathrm{mL}$ of penicillin and 100 units $/ \mathrm{mL}$ of streptomycin in a humidified atmosphere containing $5 \% \mathrm{CO}_{2}$ at $37^{\circ} \mathrm{C}$.

For experiments, cells were seeded at a density of $1 \times 10^{5} / \mathrm{cm}^{2}$ in plates and grown to $70 \%-80 \%$ confluency. MES 23.5 cells were pretreated with $100 \mu \mathrm{M}$ urate (Sigma, Ronkonkoma, NY, USA) for $30 \mathrm{~min}$, and then co-incubated with $50 \mu \mathrm{M}$ 1-methyl-4-phenylpyridinium $\left(\mathrm{MPP}^{+}\right.$; Sigma, Ronkonkoma, NY, USA) for another $24 \mathrm{~h}$. To investigate urate transport mechanism, MES23.5 cells were pretreated for $30 \mathrm{~min}$ with $500 \mu \mathrm{M}$ uricosuric probenecid (Sigma, Ronkonkoma, NY, USA) to inhibit Glut9-mediated urate transport capacity or $20 \mu \mathrm{M}$ pifithrin- $\alpha$ (Sigma, Ronkonkoma, NY, USA) to inhibit p53 transcriptional activity prior to the addition of $100 \mu \mathrm{M}$ urate followed by co-incubation with $50 \mu \mathrm{M} \mathrm{MPP}^{+}$ for $24 \mathrm{~h}$.

\section{Cell Viability Measurement}

Cell viability was measured using 3-(4,5-dimethyl-2-thiazolyl)2,5-diphenyl-2-H-tetrazolium bromide (MTT) assay. At the end of treatment, culture medium was replaced with the medium containing MTT at a final concentration of $5 \mathrm{mg} / \mathrm{mL}$ for $4 \mathrm{~h}$ at $37^{\circ} \mathrm{C}$. The insoluble formazan was then dissolved in dimethyl sulphoxide (DMSO). Cell viability was assessed at the wavelength of $494 \mathrm{~nm}$ and $630 \mathrm{~nm}$ using a microplate reader (Molecular Device, M5, Sunnyvale, CA, USA).

\section{Flow Cytometric Measurement of Reactive Oxygen Species (ROS) and Mitochondrial Transmembrane Potential $(\Delta \Psi \mathrm{m})$}

The dye $2^{\prime}, 7^{\prime}$-dichlorofluorescein diacetate $\left(\mathrm{H}_{2} \mathrm{DCFDA}\right)$ can penetrate into cells, whose oxidation to form the highly fluorescent $2^{\prime}, 7^{\prime}$-dichlorofluorescein (DCF) is proportional to ROS generation. Rhodamine123 (Rh123) can be accumulated into mitochondria via facilitated diffusion. The uptake of Rh123 is decreased due to the reduction of $\Delta \Psi \mathrm{m}$, which can serve as an indicator of $\Delta \Psi \mathrm{m}$.

Flow cytometry (Becton Dickinson, USA) was used to measure the changes of ROS and $\Delta \Psi \mathrm{m}$. At the end of treatment, cells were washed with 2-[4-(2-Hydroxyethyl)-1piperazinyl] ethanesulfonic acid (HEPES)-buffered saline (HBS) for three times followed by incubation with $5 \mu \mathrm{M} \mathrm{H}_{2}$ DCFDA (Molecular Probes, Eugene, OR, USA) or $5 \mu \mathrm{M}$ Rh123 (Sigma, Ronkonkoma, NY, USA) for $30 \mathrm{~min}$ at $37^{\circ} \mathrm{C}$ in dark. After washing three times with HBS, labeled cells were resuspended in $1 \mathrm{~mL}$ HBS. For analysis, $488 \mathrm{~nm}$ excitation and $525 \mathrm{~nm}$ emission wavelengths were used to assess 10,000 cells for each group. The results were presented as Fluorescence 1-Histogram (FL1-H), setting the gated regions $\mathrm{M} 1$ and $\mathrm{M} 2$ as markers 
to observe the fluorescence intensity using CellQuest Software (Becton Dickinson, USA). Fluorescence values of the control were normalized to $100 \%$. The results were expressed as the percentage of fluorescence intensity for each experimental group relative to the control.

\section{Animals and Treatment}

Male 10 month-old UOx KO mice and wild type (WT) littermates mice were used in the present study. The generation of UOx KO mice using a high-performance TALEN strategy was previously described ( $\mathrm{Lu}$ et al., 2018). Animals were maintained at constant temperature and humidity on a 12 -h light/dark cycle with free access to food and water. Mice were intraperitoneal injected with 1-methyl-4-phenyl-1,2,3,6tetrahydropyridine (MPTP; Sigma, Ronkonkoma, NY, USA) at the dose of $30 \mathrm{mg} / \mathrm{kg}$, or its vehicle saline solution once per day for five consecutive days. Twenty-four hours after the last injection of MPTP, blood and brains were collected for the following studies. One side of the SN was isolated to assess tyrosine hydroxylase $(\mathrm{TH})$ protein levels and striatum was isolated for urate measurement. The other side of the brain was fixed in $4 \%$ paraformaldehyde (PFA) for TH immunofluorescent staining. This study was carried out in accordance with the recommendations of National Institutes of Health Guidelines for the Care and Use of Laboratory Animals. The protocol was approved by the Animal Ethics Committee of Qingdao University.

\section{Serum, Striatal and Intracellular Urate Measurement}

For serum urate measurement, mice blood was collected via inner canthus into an anticoagulant tube and then incubated at room temperature for $1 \mathrm{~h}$. After centrifugation at $1500 \mathrm{~g}$ for $10 \mathrm{~min}$, serum was transferred into Eppendorf tubes and stored at $-80^{\circ} \mathrm{C}$ for urate measurement.

The dissection of striatum was performed as previously described (Glowinski and Iversen, 1966). Briefly, after the removal of rhombencephalon from the brain, a transverse section was made at the level of optic chiasma which separated the cerebrum into two parts. The striatum was dissected with the external walls of the lateral ventricles as medial limits and the corpus callosum as lateral limits. Striatum tissues were weighed and homogenized in $200 \mu \mathrm{L}$ assay buffer. Then, the homogenate was spinned down at $12,000 \mathrm{~g}$ for $15 \mathrm{~min}$ at $4^{\circ} \mathrm{C}$. The supernatant was collected for the striatal urate measurement.

To assess intracellular urate levels, at the end of treatment, MES23.5 cells were washed twice with phosphate-buffered saline (PBS) and harvested. Then, cells were lysed with $200 \mu \mathrm{L}$ assay buffer and centrifuged at $12,000 \mathrm{~g}$ for $15 \mathrm{~min}$ at $4^{\circ} \mathrm{C}$. The resulting supernatant was transferred into Eppendorf tubes for intracellular urate measurement. The protein concentration was determined using the BCA protein assay kit (Thermo Fisher Scientific, USA).

Serum, striatal and intracellular urate levels were assessed using the Uric Acid Fluorometric Assay Kit (BioVision, Milpitas, CA, USA) according to the manufacturer's instructions. In brief, $20 \mu \mathrm{L}$ samples were mixed with $30 \mu \mathrm{L}$ assay buffer in a 96-well plate, followed by adding $50 \mu \mathrm{L}$ reaction mixture containing $46 \mu \mathrm{L}$ assay buffer, $2 \mu \mathrm{L}$ probe and $2 \mu \mathrm{L}$ enzyme mix. The mixtures were then incubated at $37^{\circ} \mathrm{C}$ for $30 \mathrm{~min}$ in dark. Fluorescence was measured at $535 \mathrm{~nm}$ excitation and $590 \mathrm{~nm}$ emission wavelengths using a microplate reader. Urate concentration was determined with a standard curve obtained from the defined concentrations of urate. Serum, striatal and intracellular urate concentration were expressed as $\mu \mathrm{M}, \mathrm{nmol} / \mathrm{mg}$ tissue and $\mu \mathrm{mol} / \mathrm{g}$ protein, respectively.

\section{Immunofluorescent Staining}

The brain tissues were sliced into $20 \mu \mathrm{m}$-thick sections for $\mathrm{TH}$ immunofluorescent staining. After blocking with $10 \%$ goat serum for $30 \mathrm{~min}$, the sections were incubated with anti-TH antibody (1:1000, Sigma, Ronkonkoma, NY, USA) overnight at $4^{\circ} \mathrm{C}$. Then, sections were incubated with Alexa Fluor ${ }^{\circledR}$ 555 donkey anti-rabbit $\operatorname{IgG}(\mathrm{H}+\mathrm{L})$ secondary antibody $(1: 500$, Invitrogen, Carlsbad, CA, USA) for $1 \mathrm{~h}$ at room temperature, and images were obtained by immunofluorescent microscopy (Observer A1, Zeiss, Germany). The dopaminergic neurons in the SN were outlined on the basis of TH immunofluorescent staining. The number of $\mathrm{TH}^{+}$neurons in the $\mathrm{SN}$ was determined using stereological quantification as previously described (Zhang et al., 2015).

\section{Western Blot}

Samples from animals and cells were digested with RIPA lysis buffer $(50 \mathrm{mM}$ Tris- $\mathrm{HCl}, 150 \mathrm{mM} \mathrm{NaCl}, 1 \%$ Nonidet40, $0.5 \%$ sodium deoxycholate, $1 \mathrm{mM}$ EDTA, $1 \mathrm{mM}$ PMSF) and protease inhibitors (Roche Diagnostics, Germany) for $30 \mathrm{~min}$. The lysate was centrifuged at $12,000 \mathrm{~g}$ for $20 \mathrm{~min}$ at $4^{\circ} \mathrm{C}$, and the supernatant was used for analysis. Protein concentration was established using the $\mathrm{BCA}$ protein assay kit (Thermo Fisher Scientific, USA). A total of $25 \mu \mathrm{g}$ of protein was electrophoresed and transferred to PVDF membranes. After blocking with $10 \%$ non-fat milk for $2 \mathrm{~h}$ at room temperature, the membranes were incubated with anti-TH antibody (1:1000, Sigma, Ronkonkoma, NY, USA), anti-superoxide dismutase 1 (SOD1) antibody (1:1000, Santa Cruz Biotechnology, Dallas, TX, USA), anti-Glut9 antibody (1:1000, Abcam, UK) and anti-p53 antibody (1:1000, Cell Signaling Technology, Danvers, MA, USA) overnight at $4^{\circ} \mathrm{C}$. Membranes were incubated with horseradish peroxidaseconjugated secondary antibodies (1:10,000, Santa Cruz Biotechnology, Dallas, TX, USA) for $1 \mathrm{~h}$ at room temperature. Blots were visualized with UVP Image System and quantified with ImageJ Software.

\section{Statistical Analysis}

SPSS 17.0 was used to analyze the data. One-way analysis of variance (ANOVA) followed by the Student-Newman-Keuls test was used to compare difference between means in more than two groups. Data were presented as mean \pm SEM. A probability of $P<0.05$ was taken to indicate statistical significance. 


\section{RESULTS}

\section{Increased Intracellular Urate Was Responsible for Its Anti-oxidative Effects in MES23.5 Cells}

In this study, we observed that $\mathrm{MPP}^{+}$treatment for $24 \mathrm{~h}$ resulted in a significant decrease in cell viability in a dose-dependent manner in MES23.5 cells (Figure 1A). Considering that $50 \mu \mathrm{M}$ $\mathrm{MPP}^{+}$reduced cell viability by $35.6 \%$ compared with the control, which was the minimum concentration to cause cell damage, $50 \mu \mathrm{M} \mathrm{MPP}^{+}$was chosen for the following experiments. Pretreatment with indicated concentrations of urate for $30 \mathrm{~min}$ could antagonize $\mathrm{MPP}^{+}$-induced cytotoxicity at a concentration range of 100-400 $\mu \mathrm{M}$ (Figure 1B). The lowest effective concentration of urate was applied for the following studies.
A

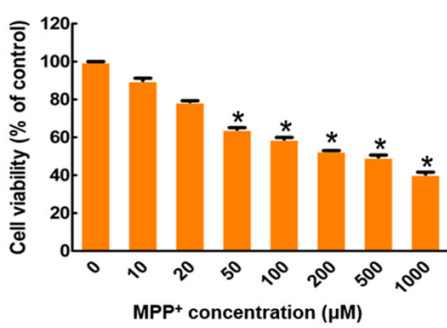

$\mathrm{MPP}+$ concentration $(\mu \mathrm{M})$

D

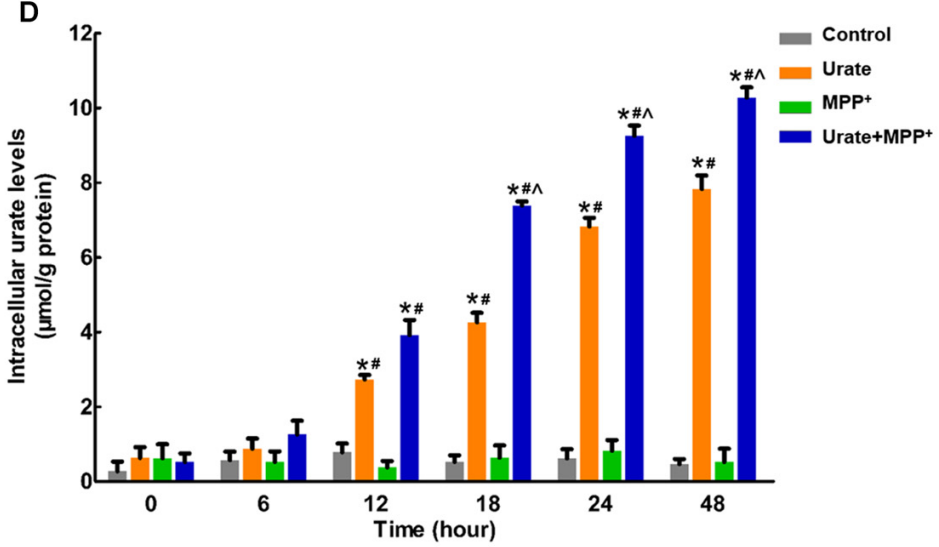

$\mathbf{F}$
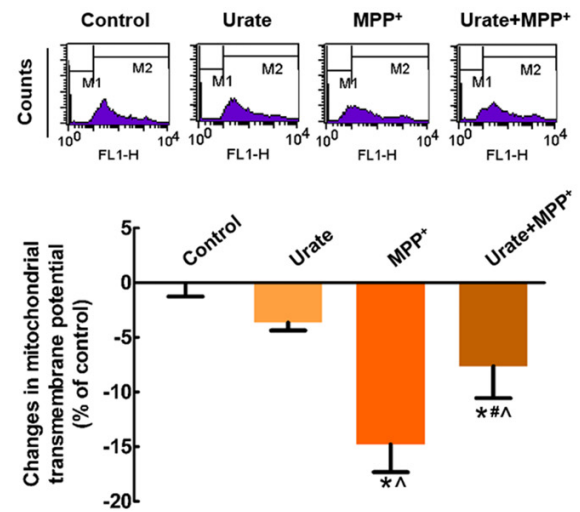

B

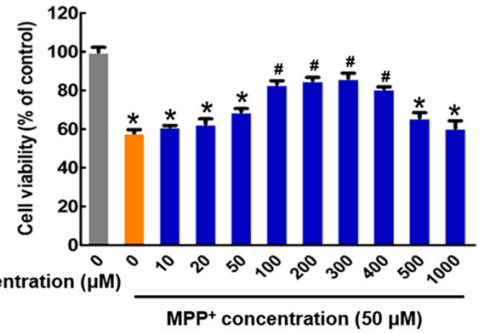

E

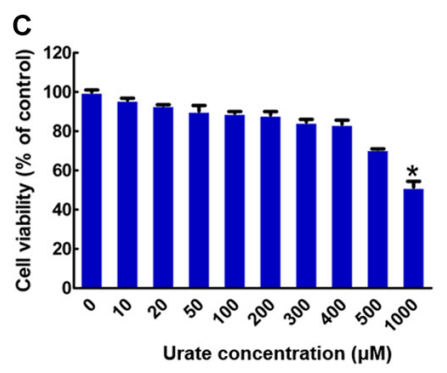

Control
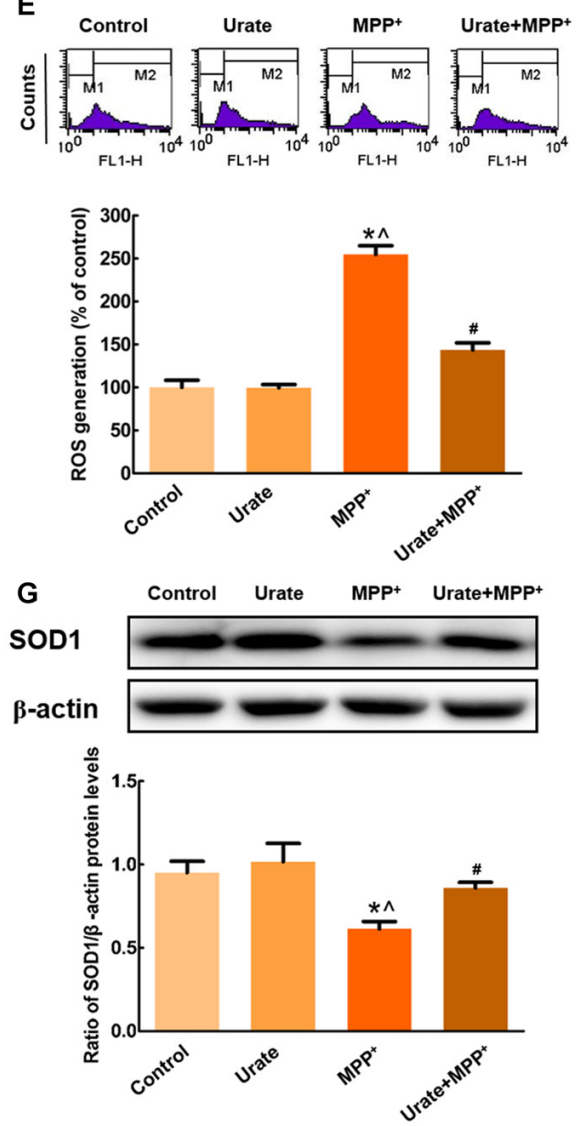

FIGURE 1 | Intracellular urate exerted anti-oxidative effects in MES23.5 cells. (A) Dose-dependent toxicity of MPP ${ }^{+}$in MES23.5 cells. Cell viability was determined by MTT assay. (B) Effects of urate on $\mathrm{MPP}^{+}$-induced cytotoxicity. Pretreatment with urate antagonized $\mathrm{MPP}^{+}$-induced reduction of cell viability at a concentration range of 100-400 $\mu \mathrm{M}$ in MES23.5 cells. (C) Effects of urate on cell viability at indicated concentrations. (D) Intracellular urate levels were detected using urate fluorometric assay. $\mathrm{MPP}^{+}$treatment induced a significant increase in intracellular urate levels compared with solely urate treatment from $18 \mathrm{~h}$. ROS generation (E) and $\Delta \Psi \mathrm{m}$ changes $\mathbf{( F )}$ of different groups were measured using flow cytometry. (G) Western blot was applied to detect SOD1 protein levels. Data were presented as the ratio of SOD1 to $\beta$-actin. Urate pretreatment could antagonize MPP+-induced excessive ROS generation, collapse of $\triangle \Psi \mathrm{m}$ and decreased SOD1 protein levels. Data were presented as mean \pm SEM. ${ }^{*} P<0.05$, compared with the control; ${ }^{*} P<0.05$, compared with the MPP ${ }^{+}$-treated group; ${ }^{\wedge} P<0.05$, compared with the urate-treated group, $n=6$. 
To preclude the possibility that urate caused any toxicity, cells were treated with different doses of urate alone for $24 \mathrm{~h}$. The results showed that urate did not produce any toxic effects on MES23.5 cells except for the highest concentration used (1000 $\mu \mathrm{M}$; Figure 1C). Therefore, urate pretreatment could significantly antagonize $\mathrm{MPP}^{+}$-induced reduction of cell viability in MES23.5 cells.

To elucidate whether exogenous urate could be accumulated into MES23.5 cells, we measured the intracellular urate levels. As shown in Figure 1D, intracellular urate content was gradually increased in a time-dependent manner. Moreover, $\mathrm{MPP}^{+}$ treatment induced a 1.7-fold increase of intracellular urate levels compared with solely urate treatment from $18 \mathrm{~h}$. These results suggested that more urate could be accumulated into cells under oxidative stress induced by $\mathrm{MPP}^{+}$.

Then, we wanted to illustrate the effects of increased intracellular urate on $\mathrm{MPP}^{+}$-induced neurotoxicity. Excessive generation of ROS is a main reason for DNA or RNA damage, which cumulatively contributes to oxidative stress. In the present study, we found that intracellular ROS levels showed a 2.5-fold increase when incubated with $50 \mu \mathrm{M} \mathrm{MPP}^{+}$for $24 \mathrm{~h}$. While pretreated with $100 \mu \mathrm{M}$ urate, ROS generation was significantly attenuated (Figure 1E). Moreover, the changes in $\Delta \Psi \mathrm{m}$ were a marker of mitochondrial function, which was also involved in oxidative stress. As shown in Figure 1F, urate pretreatment could remarkably antagonize $\mathrm{MPP}^{+}$-induced decrease of $\Delta \Psi \mathrm{m}$. Next, we measured the protein levels of SOD1, which was a highly potent anti-oxidative agent. It was observed that SOD1 protein levels were decreased by $35.7 \%$ in cells treated with $\mathrm{MPP}^{+}$, and this effect could be partially reversed by urate pretreatment (Figure 1G). The above results indicated that increased intracellular urate could antagonize $\mathrm{MPP}^{+}$-induced neurotoxicity by its anti-oxidative properties.

\section{Up-regulated Glut9 Accounted for the Increased Intracellular Urate Levels}

Next question is how urate was transported into the cells to exert its anti-oxidative effects. Since the accumulation of urate was transporter-mediated, the expression of high-capacity urate transporter Glut9 was detected in MES23.5 cells. As shown in Figure 2A, Glut9 protein levels were significantly increased by $48.9 \%$ when exposed to $\mathrm{MPP}^{+}$compared with the control, indicating an increased cellular ability to transport urate. Then, we specifically inhibited Glut9-mediated urate transport with probenecid, which was also the widely used gout drug. As

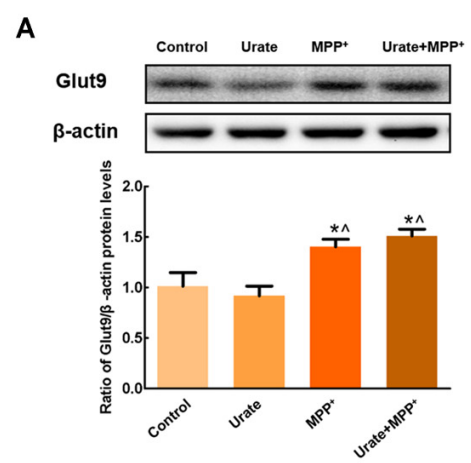

C
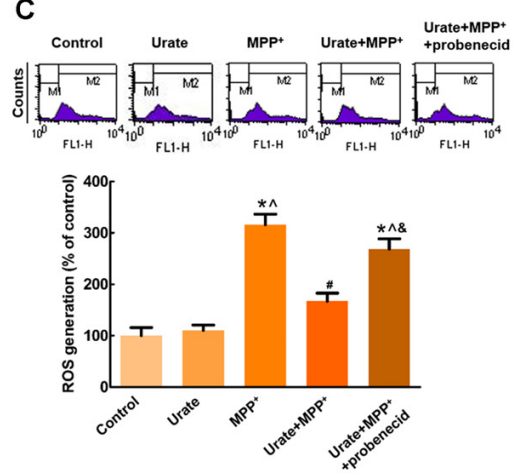

B

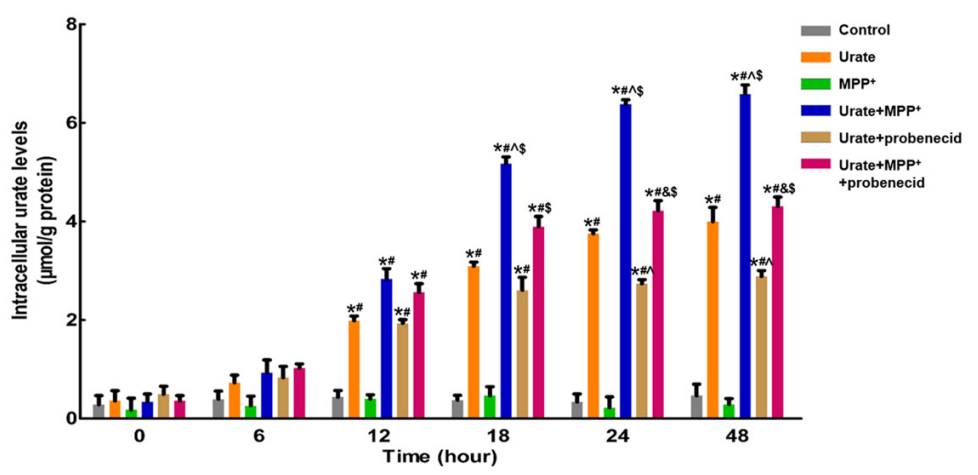

D

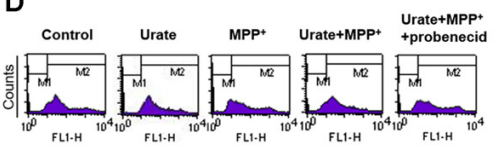

E
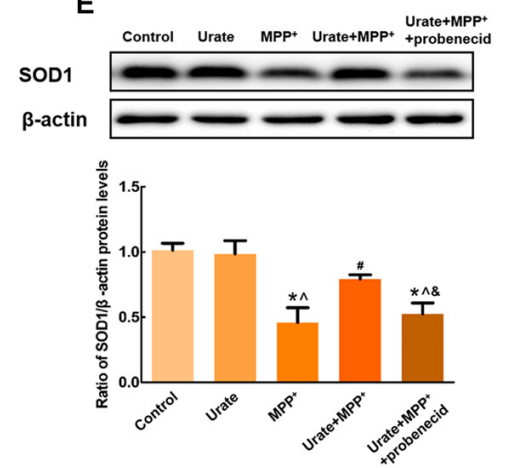

FIGURE 2 | Increased intracellular urate levels were mediated by Glut9. (A) Western blot was applied to detect Glut9 protein levels. Data were presented as the ratio of Glut9 to $\beta$-actin. Glut9 protein levels were remarkably up-regulated in MPP ${ }^{+}$-treated MES23.5 cells. (B) Intracellular urate levels were detected using urate fluorometric assay. After probenecid treatment, intracellular urate levels were obviously decreased. ROS generation (C) and $\Delta \Psi \mathrm{m}$ changes (D) of different groups were measured using flow cytometry. (E) Western blot was applied to detect SOD1 protein levels. Data were presented as the ratio of SOD1 to $\beta$-actin. Pretreatment with probenecid completely blocked the anti-oxidative effects of urate in MES23.5 cells. Data were presented as mean \pm SEM. ${ }^{*} P<0.05$, compared with the control; ${ }^{P} P<0.05$, compared with the $\mathrm{MPP}^{+}$-treated group; $\wedge P<0.05$, compared with the urate-treated group; \& $P<0.05$, compared with the urate + $\mathrm{MPP}^{+}$-treated group; ${ }^{\$} P<0.05$, compared with the urate + probenecid-treated group, $n=6$. 
expected, probenecid could significantly diminish urate uptake from $24 \mathrm{~h}$ and intracellular urate levels showed a 1.5-fold decrease with probenecid treatment when compared with urate $+\mathrm{MPP}^{+}$group (Figure 2B). Moreover, we detected the effects of urate on $\mathrm{MPP}^{+}$-induced neurotoxicity in the presence of probenecid. Pretreatment of cells with probenecid completely blocked the anti-oxidative effects of urate, resulting in increased ROS generation (Figure 2C), decreased $\Delta \Psi \mathrm{m}$ (Figure 2D) and SOD1 protein levels (Figure 2E). Together, these results indicated that increased intracellular urate levels involved in its neuroprotection were mediated by the up-regulated Glut 9 .

\section{p53 Was Responsible for the Up-regulation of Glut9}

The above results suggested that urate could be accumulated into the cells in the presence of urate transporter Glut9. Next, we attempted to explore the possible molecular mechanisms involved in the increased Glut9 expression under oxidative stress. Notably, Glut9 was previously reported to be a direct transcriptional target of tumor suppressor p53 (Itahana et al., 2015). In the present study, we found that $\mathrm{p} 53$ protein levels were remarkably increased by $68.3 \%$ in $\mathrm{MPP}^{+}$-treated MES23.5 cells, which in turn increased the expression of Glut9 (Figure 3A). When incubated with pifithrin- $\alpha$, which could inhibit the transcriptional activity of $\mathrm{p} 53$, the increased expression of Glut9 was found to be abolished. These results indicated that the activation of p53 was responsible for the up-regulation of Glut9 triggered by $\mathrm{MPP}^{+}$. Furthermore, under $\mathrm{MPP}^{+}$-induced oxidative stress conditions, there was a 1.4-fold decrease in intracellular urate levels with pifithrin- $\alpha$ treatment from $24 \mathrm{~h}$ (Figure 3B). Pretreatment with pifithrin- $\alpha$ could also eliminate the anti-oxidative effects of urate against $\mathrm{MPP}^{+}$in MES23.5 cells (Figures 3C-E).

\section{Up-regulated Nigral Glut9 Levels in UOx KO Mice Antagonized MPTP-Induced Neurotoxicity}

In UOx KO mice, we found that nigral Glut9 protein levels were significantly increased by $64.6 \%$ compared with those of the WT group (Figure 4A). Moreover, urate levels showed a 5.4-fold increase in serum (Figure 4B) and 2.6-fold increase in the striatum (Figure 4C) when compared with those in WT littermates, whose levels were much lower in the brain than that of the blood.
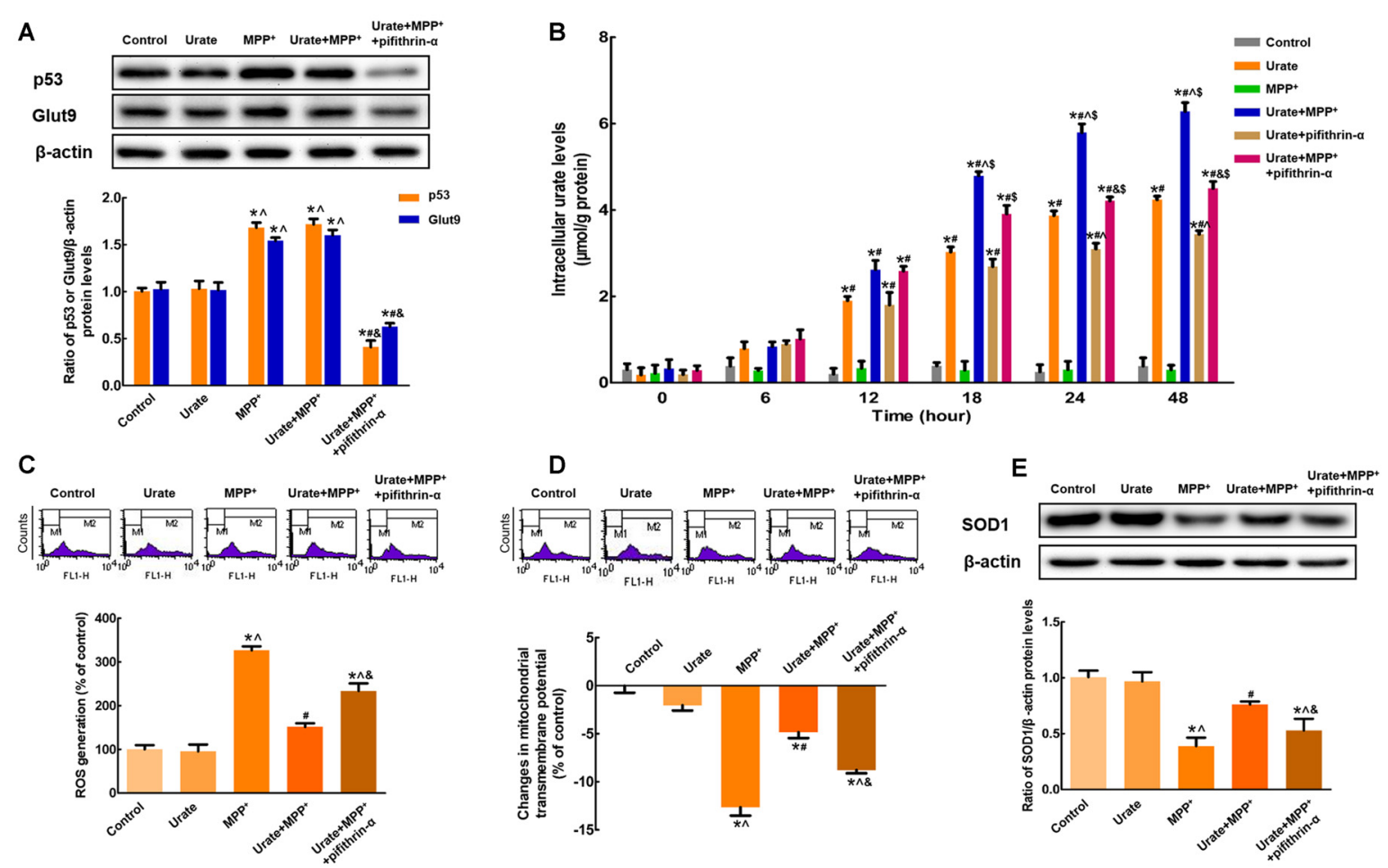

FIGURE 3 | p53 was responsible for the up-regulation of Glut9 in MPP+ -treated MES 23.5 cells. (A) Western blot was applied to detect p53 and Glut9 protein levels. Data were presented as the ratio of p53 or Glut9 to $\beta$-actin. The activation of p53 induced an increased Glut9 protein levels in MPP ${ }^{+}$-treated MES23.5 cells. Pretreatment with pifithrin- $\alpha$ reversed the up-regulation of Glut9. (B) Intracellular urate levels were detected using urate fluorometric assay. After pifithrin- $\alpha$ treatment, intracellular urate levels were decreased. ROS generation (C) and $\Delta \Psi \mathrm{m}$ changes (D) of different groups were measured using flow cytometry after the inhibition of p53. (E) Western blot was applied to detect SOD1 protein levels. Data were presented as the ratio of SOD1 to $\beta$-actin. Pretreatment with pifithrin- $\alpha$ eliminated the anti-oxidative effects of urate in MES23.5 cells. Data were presented as mean \pm SEM. ${ }^{*} P<0.05$, compared with the control; ${ }^{*} P<0.05$, compared with the $\mathrm{MPP}^{+}$-treated group; $\wedge P<0.05$, compared with the urate-treated group; $\& P<0.05$, compared with the urate + MPP ${ }^{+}$-treated group; ${ }^{\$} P<0.05$, compared with the urate + pifithrin- $\alpha$-treated group, $n=6$. 

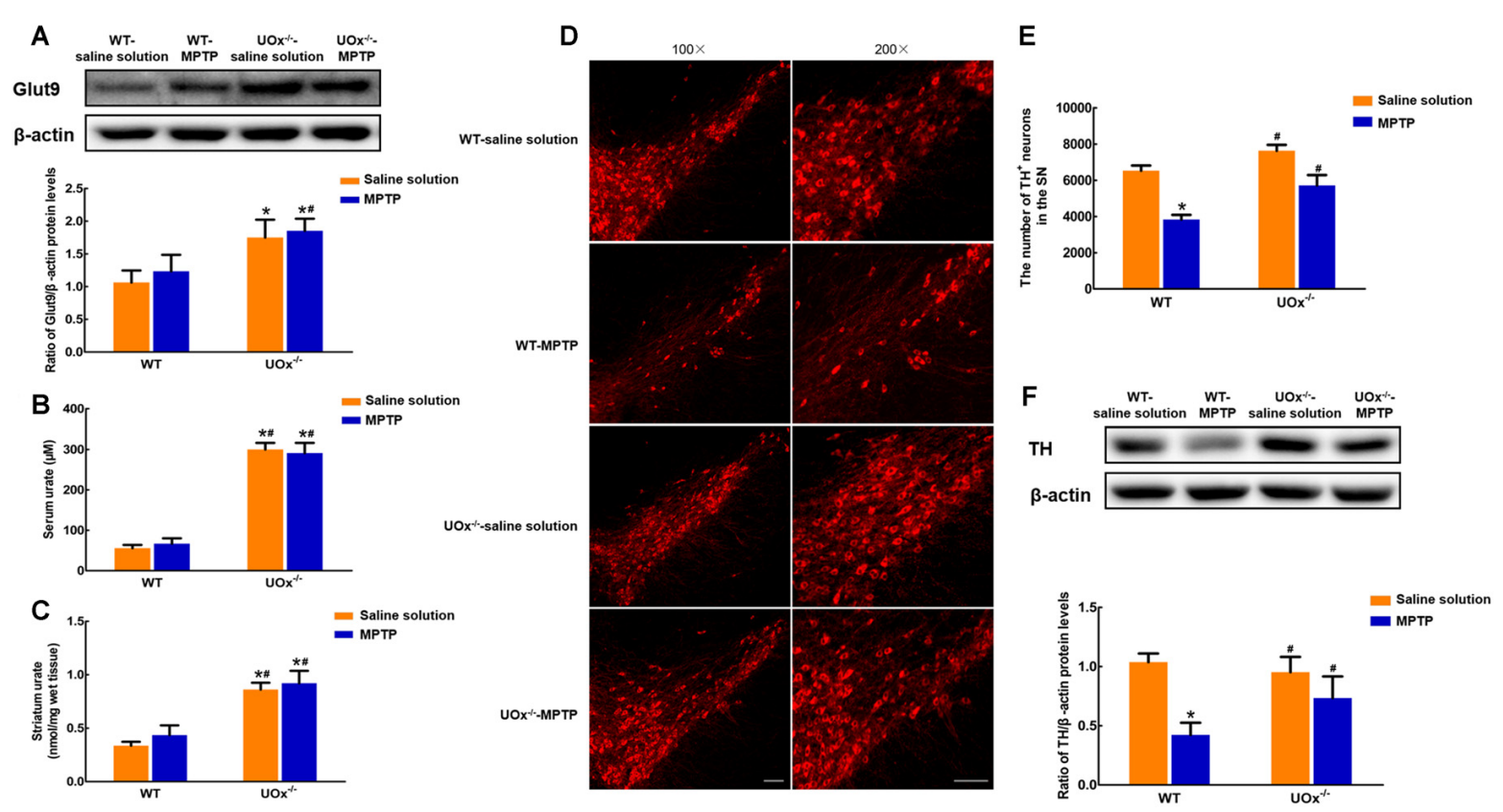

FIGURE 4 | Up-regulated nigral Glut9 alleviated MPTP-induced neurotoxicity in UOx KO mice. (A) Western blot was applied to detect Glut9 protein levels. Data were presented as the ratio of Glut9 to $\beta$-actin. The nigral Glut9 protein levels were significantly increased in UOx KO mice compared with the WT group. Urate levels were detected using urate fluorometric assay. Urate levels in serum (B) and striatum (C) were significantly increased in UOx KO mice compared with the WT group.

(D) Representative pictures showing $\mathrm{TH}^{+}$neurons in the substantia nigra (SN) of different groups determined by immunofluorescent staining. Scale bar $=100 \mu \mathrm{m}$.

(E) Group data showing the number of $\mathrm{TH}^{+}$neurons of different groups. (F) Western blot was applied to detect TH protein levels. Data were presented as the ratio of $\mathrm{TH}$ to $\beta$-actin. The loss of $\mathrm{TH}^{+}$neurons and decreased TH protein levels induced by MPTP were alleviated in UOx KO mice compared with those in WT mice. Data were presented as mean \pm SEM. ${ }^{*} P<0.05$, compared with the WT-saline solution group; ${ }^{*} P<0.05$, compared with the WT-MPTP group, $n=3$.

In MPTP-treated UOx KO mice, the reduction in the number of $\mathrm{TH}^{+}$neurons was $25.1 \%$ compared with the saline solutiontreated group. However, in WT mice, MPTP induced a $41.3 \%$ loss of $\mathrm{TH}^{+}$neurons compared with saline solution treatment (Figures 4D,E). Similar results were observed for the nigral TH protein levels. In UOx KO mice, there was a $22.9 \%$ reduction in the TH levels after MPTP injection compared with saline solution treatment, while a $59.3 \%$ reduction in the WT-MPTP group compared with the WT-saline solution group (Figure $4 \mathbf{F}$ ). The loss of $\mathrm{TH}^{+}$neurons and decreased $\mathrm{TH}$ protein levels induced by MPTP were remarkably reversed in UOx KO mice compared with those in WT littermates.

\section{DISCUSSION}

In the present study, we demonstrated that Glut9-mediated increased urate uptake was involved in the protection of dopaminergic cells against $\mathrm{MPTP} / \mathrm{MPP}^{+}$-induced neurotoxicity both in vivo and in vitro.

Urate, primarily as a weak acid, is generated from purine metabolism (So and Thorens, 2010). In the majority of mammals, urate undergoes oxidative degradation by $\mathrm{UOx}$ to form the more soluble compound allantoin. By contrast, in humans and primates, urate constitutes the end product of purine metabolism due to the absence of functional UOx. Thus, urate levels in humans are approximately 10 times more than those in most mammals, which has been hypothesized to reflect an evolutionary advantage and lengthening lifespan against aging (Mandal and Mount, 2015). Previous studies have reported that urate levels in postmortem brains of PD patients are lower compared with the control (McFarland et al., 2013). Numerous epidemiological studies have also shown serum or CSF urate levels were negatively correlated with the risk and severity of PD (de Lau et al., 2005; McFarland et al., 2013; Gao et al., 2016; Andersen et al., 2017).

In the present study, we observed a direct protection by urate against $\mathrm{MPTP} / \mathrm{MPP}^{+}$-induced neurotoxicity both in vivo and in vitro. MPTP, as a common agent for generating PD animal models (Jiang et al., 2017), is first metabolized by monoamine oxidase- $\mathrm{B}$ (MAO-B) to 1-methyl-4-phenyl2,3-dihydropyridinium $\left(\mathrm{MPDP}^{+}\right)$, and then deprotonates to generate $\mathrm{MPP}^{+}$, which can enter cells through the dopamine reuptake system and inhibit complex I of the mitochondrial respiratory chain to induce oxidative stress (Desai et al., 1996; Cassarino et al., 1999; Smeyne and Jackson-Lewis, 2005; Shen et al., 2017). Previous studies have reported that there exists xanthine oxidase enzyme in brain converting xanthine to urate, so that the brain has the capacity to generate urate in situ. Furthermore, urate generated peripherally could also access to the brain (Bowman et al., 2010). In our study, using UOx KO mice, which have been reported as a suitable model of 
hyperuricemia and more closely mimic purine metabolism in humans (Lu et al., 2018), we provided the evidence that serum and striatal urate levels were significantly elevated. Specific localization of urate transporters in brain raised the possibility that urate might be partly transported into ventricular CSF. CSF-derived urate could also increase the regional urate levels near the ventricle, for example in the striatum (Tomioka et al., 2016). In addition, MPTP could induce an increased trend of striatal urate levels, indicating that urate might be induced to alleviate the neurotoxicity triggered by MPTP. Moreover, we found that elevated urate levels could alleviate the loss of nigral dopaminergic neurons and protect MES23.5 cells against $\mathrm{MPP}^{+}$-induced cytotoxicity by its anti-oxidative properties. These findings are consistent with some previous studies. Urate treatment could attenuate the impairment of motor performance in 6-hydroxydopamine (6-OHDA)-lesioned rat models of PD (Gong et al., 2012). In vitro, urate could block cell injury induced by 6-OHDA, dopamine and rotenone in dopaminergic neurons (Jones et al., 2000; Duan et al., 2002; Zhu et al., 2012). Lowering serum and striatal urate levels by oral allopurinol potentiate striatal dopamine loss but could not exacerbate dopaminergic neuron degeneration in a dual pesticide mice model of PD (Kachroo and Schwarzschild, 2014).

Although the beneficial effects of urate have been demonstrated, the underlying molecular mechanism is still largely unknown. Urate, in fact, is a natural antioxidant and a powerful scavenger of free radicals, which accounts for more than two-thirds of the antioxidant capacity in humans (Ames et al., 1981). Recently, several studies on the mechanisms for neuroprotection by urate have focused on its anti-oxidative properties. It has been reported that urate could induce nuclear factor E2 related factor 2 (Nrf2) nuclear translocation and further regulated the expression of antioxidant response elements (ARE; Zhang et al., 2014), which in turn remarkably increase the synthesis and release of glutathione (GSH; Bakshi et al., 2015). Furthermore, protein kinase B (Akt)/glycogen synthase kinase $3 \beta$ (GSK $3 \beta$ ) pathway might be involved in the beneficial effects of urate against the toxicity of 6-OHDA (Gong et al., 2012). It should be noted that the anti-oxidative ability of urate might be dependent on its intracellular levels. Although one study reported that urate could not be accumulated into rat mesencephalic dopaminergic neurons, indicating the protective effects of urate occurred probably extracellularly (Guerreiro et al., 2009), most studies consistently agreed that exogenous urate could increase intracellular urate levels through some unknown transport mechanisms (Cipriani et al., 2012a,b; Zhang et al., 2014). This discrepancy might in part be explained by different urate measurement protocols. Thus, in the present study, we attempted to investigate the urate transport mechanism responsible for its neuroprotective effects under oxidative stress conditions.

Urate transporters, such as Glut9, URAT1, ABCG2 and OAT, play a key role in maintaining urate homeostasis. Glut9, encoded

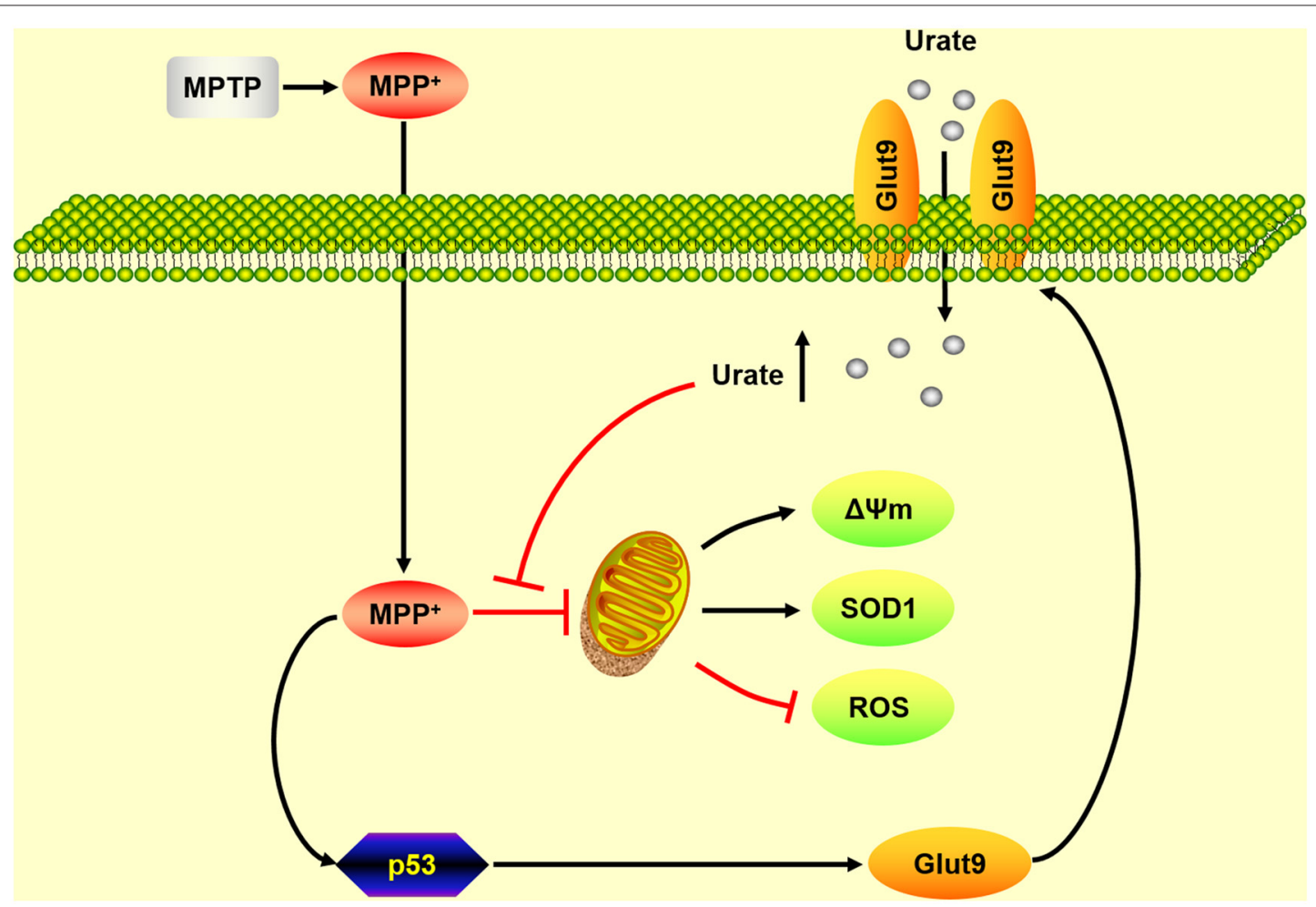

FIGURE 5 | A schematic diagram of the mechanism underlying the neuroprotective effects of urate on dopaminergic neurons. Under oxidative stress induced by $\mathrm{MPP}^{+}$, the activation of p53 induced an increased expression of its transcriptional target Glut9. Increased urate uptake mediated by Glut9 could protect dopaminergic neurons against $\mathrm{MPP}^{+}$-induced neurotoxicity by its anti-oxidative properties. 
by $S L C 2 A 9$ gene, is a newly identified high-capacity urate transporter (Caulfield et al., 2008; Vitart et al., 2008; Preitner et al., 2009). It is widely expressed in liver, lung, heart, kidney, intestine, leucocytes and chondrocytes. Recent studies show that Glut9 is also observed in neurons and brain capillaries (Tomioka et al., 2016). Glut9-mediated urate transport is probably not a coupled transport system but rather a urate uniporter (Bibert et al., 2009). Genome-wide association studies (GWAS) has identified variation in SLC2A9 gene is the strongest known genetic determinant of plasma urate concentration in humans (Dehghan et al., 2008; Köttgen et al., 2013). An interaction between genome-wide variant and serum urate levels may be a predictor of disease progression and important step for personalizing prognosis in PD (Nazeri et al., 2015). In this study, we found that the expression of Glut9 was up-regulated with $\mathrm{MPP}^{+}$treatment, resulting in an increased capacity for urate uptake.

Notably, recent studies have reported that SLC2A9 is a direct transcriptional target of p53 (Itahana et al., 2015), which further regulates multiple antioxidant genes, implying a substantial anti-oxidative function of p53-dependent pathway in the protection of cells (Tan et al., 1999; Bensaad et al., 2006; Cano et al., 2009; Hu et al., 2010; Zhou et al., 2013). A growing number of signals can activate p53, including DNA damage, oncogene activation, nitrative and oxidative stress, hypoxia and more (Horn and Vousden, 2007). In the present study, we found that the expression of p53 was remarkably increased when exposed to $\mathrm{MPP}^{+}$, and further induced the increased Glut9 protein levels. Therefore, the activation of p53 played a causal role in the up-regulation of Glut9. As a result, the transport of urate into cells mediated by Glut9 was increased. After the application of probenecid or pifithrin- $\alpha$, intracellular urate levels were significantly decreased and its neuroprotective effects were also found to be abolished. The ability to adapt to oxidative stress is an important component of cellular defense strategy in mammalian cells (Wiese et al., 1995). In this study, the relatively high intracellular urate levels may serve as an endogenous compensatory mechanism for resistance to oxidative stress. These adaptive effects are accompanied by, and may be consequences of defects in cellular anti-oxidative stress system.

\section{REFERENCES}

Alonso, A., Rodríguez, L. A., Logroscino, G., and Hernán, M. A. (2007). Gout and risk of Parkinson disease: a prospective study. Neurology 69, 1696-1700. doi: 10.1212/01.wnl.0000279518.10072.df

Ames, B. N., Cathcart, R., Schwiers, E., and Hochstein, P. (1981). Uric acid provides an antioxidant defense in humans against oxidant- and radical-caused aging and cancer: a hypothesis. Proc. Natl. Acad. Sci. U S A 78, 6858-6862. doi: 10.1073/pnas.78.11.6858

Andersen, A. D., Binzer, M., Stenager, E., and Gramsbergen, J. B. (2017). Cerebrospinal fluid biomarkers for Parkinson's disease-a systematic review. Acta Neurol. Scand. 135, 34-56. doi: 10.1111/ane.12590

Ascherio, A., LeWitt, P. A., Xu, K., Eberly, S., Watts, A., Matson, W. R., et al. (2009). Urate as a predictor of the rate of clinical decline in Parkinson disease. Arch. Neurol. 66, 1460-1468. doi: 10.1001/archneurol.2009.247

Ascherio, A., and Schwarzschild, M. A. (2016). The epidemiology of Parkinson's disease: risk factors and prevention. Lancet Neurol. 15, 1257-1272. doi: 10.1016/S1474-4422(16)30230-7
As summarized in Figure 5, our present findings suggest that up-regulation of Glut9, which was caused by the activation of $\mathrm{p53}$, was responsible for the increased urate uptake in the $\mathrm{MPP}^{+}$-induced cell model and the MPTP-induced mice model of PD. Increased intracellular urate antagonized $\mathrm{MPP}^{+}$. induced excessive ROS generation, collapse of $\Delta \Psi \mathrm{m}$ and decreased SOD1 levels to exert its anti-oxidative effects. Our study demonstrated that Glut9-mediated urate uptake was essential for its neuroprotective effects which strengthened the rationale for exploring urate-elevating strategies as potential therapeutic targets for PD. Nevertheless, what is considered a "normal range" without increasing systemic urate levels to avoid associated side effects should be further investigated.

\section{AUTHOR CONTRIBUTIONS}

$\mathrm{HJ}$ and $\mathrm{MB}$ conceived the project and designed the study. $\mathrm{MB}, \mathrm{QJ}$ and $\mathrm{XD}$ performed the experiments, analyzed data and interpreted results. $\mathrm{MB}$ wrote the manuscript. HJ and QJ reviewed and edited the manuscript. All authors have read and approved the final version of the manuscript.

\section{FUNDING}

This work was supported by the National Natural Science Foundation of China (NSFC; 31771110, 31471114, 814300 24), National Key Research and Development Program of China (2016YFC1306500), the Key Research and Development Program of Shandong Province (216GSF201053), Qingdao Municipal Science and Technology Project (16-2-2-nsh), open project program of the State Key Laboratory of Neuroscience (SKLN-201607) and Taishan Scholars Construction Project.

\section{ACKNOWLEDGMENTS}

We thank Prof. Chang-Gui Li (the Metabolic Disease Institute of Qingdao University, Qingdao, China) for the kind gift of UOx KO mice.

Bakshi, R., Zhang, H., Logan, R., Joshi, I., Xu, Y., Chen, X., et al. (2015). Neuroprotective effects of urate are mediated by augmenting astrocytic glutathione synthesis and release. Neurobiol. Dis. 82, 574-579. doi: 10.1016/j. nbd.2015.08.022

Becker, B. F. (1993). Towards the physiological function of uric acid. Free Radic. Biol. Med. 14, 615-631. doi: 10.1016/0891-5849(93)90143-i

Bensaad, K., Tsuruta, A., Selak, M. A., Vidal, M. N., Nakano, K., Bartrons, R., et al. (2006). TIGAR, a p53-inducible regulator of glycolysis and apoptosis. Cell 126, 107-120. doi: 10.1016/j.cell.2006.05.036

Bibert, S., Hess, S. K., Firsov, D., Thorens, B., Geering, K., Horisberger, J. D., et al. (2009). Mouse GLUT9: evidences for a urate uniporter. Am J. Physiol. Renal Physiol. 297, F612-F619. doi: 10.1152/ajprenal.001 39.2009

Bowman, G. L., Shannon, J., Frei, B., Kaye, J. A., and Quinn, J. F. (2010). Uric acid as a CNS antioxidant. J. Alzheimers Dis. 19, 1331-1336. doi: 10.3233/JAD-2010 $-1330$

Cano, C. E., Gommeaux, J., Pietri, S., Culcasi, M., Garcia, S., Seux, M., et al. (2009). Tumor protein 53-induced nuclear protein 1 is a major mediator of 
p53 antioxidant function. Cancer Res. 69, 219-226. doi: 10.1158/0008-5472. CAN-08-2320

Cassarino, D. S., Parks, J. K., Parker, W. D. Jr., and Bennett, J. P. Jr. (1999). The parkinsonian neurotoxin $\mathrm{MPP}^{+}$opens the mitochondrial permeability transition pore and releases cytochrome $c$ in isolated mitochondria via an oxidative mechanism. Biochim. Biophys. Acta 1453, 49-62. doi: 10.1016/s09254439(98)00083-0

Caulfield, M. J., Munroe, P. B., O’Neill, D., Witkowska, K., Charchar, F. J., Doblado, M., et al. (2008). SLC2A9 is a high-capacity urate transporter in humans. PLoS Med. 5:e197. doi: 10.1371/journal.pmed.0050197

Church, W. H., and Ward, V. L. (1994). Uric acid is reduced in the substantia nigra in Parkinson's disease: effect on dopamine oxidation. Brain Res. Bull. 33, 419-425. doi: 10.1016/0361-9230(94)90285-2

Cipriani, S., Desjardins, C. A., Burdett, T. C., Xu, Y., Xu, K., and Schwarzschild, M. A. (2012a). Protection of dopaminergic cells by urate requires its accumulation in astrocytes. J. Neurochem. 123, 172-181. doi: 10.1111/j.1471-4159.2012.07820.x

Cipriani, S., Desjardins, C. A., Burdett, T. C., Xu, Y., Xu, K., and Schwarzschild, M. A. (2012b). Urate and its transgenic depletion modulate neuronal vulnerability in a cellular model of Parkinson's disease. PLoS One 7:e37331. doi: 10.1371/journal.pone.0037331

Davis, J. W., Grandinetti, A., Waslien, C. I., Ross, G. W., White, L. R., and Morens, D. M. (1996). Observations on serum uric acid levels and the risk of idiopathic Parkinson's disease. Am. J. Epidemiol. 144, 480-484. doi: 10.1093/oxfordjournals.aje.a008954

Dehghan, A., Köttgen, A., Yang, Q., Hwang, S. J., Kao, W. L., Rivadeneira, F., et al. (2008). Association of three genetic loci with uric acid concentration and risk of gout: a genome-wide association study. Lancet 372, 1953-1961. doi: 10.1016/S0140-6736(08)61343-4

de Lau, L. M., Koudstaal, P. J., Hofman, A., and Breteler, M. M. (2005). Serum uric acid levels and the risk of Parkinson disease. Ann. Neurol. 58, 797-800. doi: 10.1002/ana.20663

Desai, V. G., Feuers, R. J., Hart, R. W., and Ali, S. F. (1996). MPP ${ }^{+}$-induced neurotoxicity in mouse is age-dependent: evidenced by the selective inhibition of complexes of electron transport. Brain Res. 715, 1-8. doi: 10.1016/00068993(95)01255-9

Duan, W., Ladenheim, B., Cutler, R. G., Kruman, I. I., Cadet, J. L., and Mattson, M. P. (2002). Dietary folate deficiency and elevated homocysteine levels endanger dopaminergic neurons in models of Parkinson's disease. J. Neurochem. 80, 101-110. doi: 10.1046/j.0022-3042.2001.00676.x

Facheris, M. F., Hicks, A. A., Minelli, C., Hagenah, J. M., Kostic, V., Campbell, S., et al. (2011). Variation in the uric acid transporter gene SLC2A9 and its association with AAO of Parkinson's disease. J. Mol. Neurosci. 43, 246-250. doi: 10.1007/s12031-010-9409-y

Fang, P., Li, X., Luo, J. J., Wang, H., and Yang, X. F. (2013). A doubleedged sword: uric acid and neurological disorders. Brain Disord. Ther. 2:109. doi: 10.4172/2168-975x.1000109

Gao, X., Chen, H., Choi, H. K., Curhan, G., Schwarzschild, M. A., and Ascherio, A. (2008). Diet, urate, and Parkinson's disease risk in men. Am. J. Epidemiol. 167, 831-838. doi: 10.1093/aje/kwm385

Gao, X., O’Reilly, É. J., Schwarzschild, M. A., and Ascherio, A. (2016). Prospective study of plasma urate and risk of Parkinson disease in men and women. Neurology 86, 520-526. doi: 10.1212/WNL.0000000000002351

Glowinski, J., and Iversen, L. L. (1966). Regional studies of catecholamines in the rat brain. I. The disposition of $\left[{ }^{3} \mathrm{H}\right]$ norepinephrine, $\left[{ }^{3} \mathrm{H}\right]$ dopamine and $\left[{ }^{3} \mathrm{H}\right]$ dopa in various regions of the brain. J. Neurochem. 13, 655-669. doi: 10.1111/j.1471-4159.1966.tb09873.x

Gong, L., Zhang, Q. L., Zhang, N., Hua, W. Y., Huang, Y. X., Di, P. W., et al. (2012). Neuroprotection by urate on 6-OHDA-lesioned rat model of Parkinson's disease: linking to Akt/GSK3 $\beta$ signaling pathway. J. Neurochem. 123, 876-885. doi: $10.1111 /$ jnc. 12038

González-Aramburu, I., Sánchez-Juan, P., Jesús, S., Gorostidi, A., FernándezJuan, E., Carrillo, F., et al. (2013). Genetic variability related to serum uric acid concentration and risk of Parkinson's disease. Mov. Disord. 28, 1737-1740. doi: $10.1002 / \mathrm{mds} .25507$

Guerreiro, S., Ponceau, A., Toulorge, D., Martin, E., Alvarez-Fischer, D., Hirsch, E. C., et al. (2009). Protection of midbrain dopaminergic neurons by the end-product of purine metabolism uric acid: potentiation by low-level depolarization. J. Neurochem. 109, 1118-1128. doi: 10.1111/j.1471-4159.2009. 06040.x

Hayden, M. R., and Tyagi, S. C. (2004). Uric acid: a new look at an old risk marker for cardiovascular disease, metabolic syndrome, and type 2 diabetes mellitus: the urate redox shuttle. Nutr. Metab. 1:10. doi: 10.2147/dmso. s61438

Horn, H. F., and Vousden, K. H. (2007). Coping with stress: multiple ways to activate p53. Oncogene 26, 1306-1316. doi: 10.1038/sj.onc.1210263

Hornykiewicz, O. (1998). Biochemical aspects of Parkinson's disease. Neurology 51, S2-S9. doi: 10.1212/WNL.51.2_Suppl_2.S2

Hu, W., Zhang, C., Wu, R., Sun, Y., Levine, A., and Feng, Z. (2010). Glutaminase 2, a novel p53 target gene regulating energy metabolism and antioxidant function. Proc. Natl. Acad. Sci. U S A 107, 7455-7460. doi: 10.1073/pnas.1001006107

Itahana, Y., Han, R., Barbier, S., Lei, Z., Rozen, S., and Itahana, K. (2015). The uric acid transporter SLC2A9 is a direct target gene of the tumor suppressor p53 contributing to antioxidant defense. Oncogene 34, 1799-1810. doi: 10.1038/onc.2014.119

Jenner, P., and Olanow, C. W. (1998). Understanding cell death in Parkinson's disease. Ann. Neurol. 44, S72-S84. doi: 10.1002/ana.410440712

Jiang, H., Wang, J., Rogers, J., and Xie, J. (2017). Brain iron metabolism dysfunction in Parkinson's disease. Mol. Neurobiol. 54, 3078-3101. doi: 10.1007/s12035-016-9879-1

Jones, D. C., Gunasekar, P. G., Borowitz, J. L., and Isom, G. E. (2000). Dopamineinduced apoptosis is mediated by oxidative stress and Is enhanced by cyanide in differentiated PC12 cells. J. Neurochem. 74, 2296-2304. doi: 10.1046/j.14714159.2000.0742296.x

Kachroo, A., and Schwarzschild, M. A. (2014). Allopurinol reduces levels of urate and dopamine but not dopaminergic neurons in a dual pesticide model of Parkinson's disease. Brain Res. 1563, 103-109. doi: 10.1016/j.brainres.2014. 03.031

Köttgen, A., Albrecht, E., Teumer, A., Vitart, V., Krumsiek, J., Hundertmark, C., et al. (2013). Genome-wide association analyses identify 18 new loci associated with serum urate concentrations. Nat. Genet. 45, 145-154. doi: 10.1038/ ng. 2500

Lu, J., Hou, X., Yuan, X., Cui, L., Liu, Z., Li, X., et al. (2018). Knockout of the urate oxidase gene provides a stable mouse model of hyperuricemia associated with metabolic disorders. Kidney Int. 93, 69-80. doi: 10.1016/j.kint.2017.04.031

Mandal, A. K., and Mount, D. B. (2015). The molecular physiology of uric acid homeostasis. Annu. Rev. Physiol. 77, 323-345. doi: 10.1146/annurev-physiol021113-170343

McFarland, N. R., Burdett, T., Desjardins, C. A., Frosch, M. P., and Schwarzschild, M. A. (2013). Postmortem brain levels of urate and precursors in Parkinson's disease and related disorders. Neurodegener. Dis. 12, 189-198. doi: 10.1159/000346370

Nazeri, A., Roostaei, T., Sadaghiani, S., Chakravarty, M. M., Eberly, S., Lang, A. E., et al. (2015). Genome-wide variant by serum urate interaction in Parkinson's disease. Ann. Neurol. 78, 731-741. doi: 10.1002/ana.24504

Paganoni, S., and Schwarzschild, M. A. (2017). Urate as a marker of risk and progression of neurodegenerative disease. Neurotherapeutics 14, 148-153. doi: 10.1007/s13311-016-0497-4

Preitner, F., Bonny, O., Laverriere, A., Rotman, S., Firsov, D., Da Costa, A., et al. (2009). Glut9 is a major regulator of urate homeostasis and its genetic inactivation induces hyperuricosuria and urate nephropathy. Proc. Natl. Acad. Sci. U S A 106, 15501-15506. doi: 10.1073/pnas.0904411106

Reginato, A. M., Mount, D. B., Yang, I., and Choi, H. K. (2012). The genetics of hyperuricaemia and gout. Nat. Rev. Rheumatol. 8, 610-621. doi: 10.1038/nrrheum.2012.144

Schapira, A. H., Gu, M., Taanman, J. W., Tabrizi, S. J., Seaton, T., Cleeter, M., et al. (1998). Mitochondria in the etiology and pathogenesis of Parkinson's disease. Ann. Neurol. 44, S89-S98. doi: 10.1002/ana.410440714

Schwarzschild, M. A., Schwid, S. R., Marek, K., Watts, A., Lang, A. E., Oakes, D., et al. (2008). Serum urate as a predictor of clinical and radiographic progression in Parkinson disease. Arch. Neurol. 65, 716-723. doi: 10.1001/archneur.2008. 65.6.nct70003

Shen, X. L., Song, N., Du, X. X., Li, Y., Xie, J. X., and Jiang, H. (2017). Nesfatin-1 protects dopaminergic neurons against $\mathrm{MPP}^{+} / \mathrm{MPTP}$-induced neurotoxicity through the C-Raf-ERK1/2-dependent anti-apoptotic pathway. Sci. Rep. 7:40961. doi: 10.1038/srep40961 
Simon, K. C., Eberly, S., Gao, X., Oakes, D., Tanner, C. M., Shoulson, I., et al. (2014). Mendelian randomization of serum urate and parkinson disease progression. Ann. Neurol. 76, 862-868. doi: 10.1002/ana.24281

Smeyne, R. J., and Jackson-Lewis, V. (2005). The MPTP model of Parkinson's disease. Mol. Brain Res. 134, 57-66. doi: 10.1016/j.molbrainres.2004.09.017

So, A., and Thorens, B. (2010). Uric acid transport and disease. J. Clin. Invest. 120, 1791-1799. doi: 10.1172/JCI42344

Song, N., Wang, W., Jia, F., Du, X., Xie, A., He, Q., et al. (2017). Assessments of plasma ghrelin levels in the early stages of parkinson's disease. Mov. Disord. 32, 1487-1491. doi: 10.1002/mds.27095

Tan, M., Li, S., Swaroop, M., Guan, K., Oberley, L. W., and Sun, Y. (1999). Transcriptional activation of the human glutathione peroxidase promoter by p53. J. Biol. Chem. 274, 12061-12066. doi: 10.1074/jbc.274.17. 12061

Tomioka, N. H., Tamura, Y., Takada, T., Shibata, S., Suzuki, H., Uchida, S., et al. (2016). Immunohistochemical and in situ hybridization study of urate transporters GLUT9/URATv1, ABCG2, and URAT1 in the murine brain. Fluids Barriers CNS 13:22. doi: 10.1186/s12987-016-0046-x

Vitart, V., Rudan, I., Hayward, C., Gray, N. K., Floyd, J., Palmer, C. N., et al. (2008). SLC2A9 is a newly identified urate transporter influencing serum urate concentration, urate excretion and gout. Nat. Genet. 40, 437-442. doi: 10.1038/ng.106

Wei, W., Hemani, G., Hicks, A. A., Vitart, V., Cabrera-Cardenas, C., Navarro, P., et al. (2011). Characterisation of genome-wide association epistasis signals for serum uric acid in human population isolates. PLoS One 6:e23836. doi: 10.1371/journal.pone.0023836

Wiese, A. G., Pacifici, R. E., and Davies, K. J. (1995). Transient adaptation of oxidative stress in mammalian cells. Arch. Biochem. Biophys. 318, 231-240. doi: 10.1006/abbi.1995.1225
Wu, X. W., Muzny, D. M., Lee, C. C., and Caskey, C. T. (1992). Two independent mutational events in the loss of urate oxidase during hominoid evolution. J. Mol. Evol. 34, 78-84. doi: 10.1007/bf00163854

Zhang, Z., Du, X., Xu, H., Xie, J., and Jiang, H. (2015). Lesion of medullary catecholaminergic neurons is associated with cardiovascular dysfunction in rotenone-induced Parkinson's disease rats. Eur. J. Neurosci. 42, 2346-2355. doi: 10.1111/ejn.13012

Zhang, N., Shu, H. Y., Huang, T., Zhang, Q. L., Li, D., Zhang, G. Q., et al. (2014). Nrf2 signaling contributes to the neuroprotective effects of urate against 6-OHDA toxicity. PLoS One 9:e100286. doi: 10.1371/journal.pone. 0100286

Zhou, D., Zhan, C., Zhong, Q., and Li, S. (2013). Upregulation of sestrin-2 expression via P53 protects against 1-methyl-4-phenylpyridinium (MPP+) neurotoxicity. J. Mol. Neurosci. 51, 967-975. doi: 10.1007/s12031-013-0081-x

Zhu, T. G., Wang, X. X., Luo, W. F., Zhang, Q. L., Huang, T. T., Xu, X. S., et al. (2012). Protective effects of urate against 6-OHDA-induced cell injury in PC12 cells through antioxidant action. Neurosci. Lett. 506, 175-179. doi: 10.1016/j.neulet.2011.10.075

Conflict of Interest Statement: The authors declare that the research was conducted in the absence of any commercial or financial relationships that could be construed as a potential conflict of interest.

Copyright (C) 2018 Bi, Jiao, Du and Jiang. This is an open-access article distributed under the terms of the Creative Commons Attribution License (CC BY). The use, distribution or reproduction in other forums is permitted, provided the original author(s) and the copyright owner are credited and that the original publication in this journal is cited, in accordance with accepted academic practice. No use, distribution or reproduction is permitted which does not comply with these terms. 